Sayako Miura*

\title{
Component Sharing Across Product Categories Leads to Functional Diversification: Evidence from the Japanese Digital Audio-Visual Products Market
}

DOI 10.1515/asia-2015-0056

\begin{abstract}
This study focuses on component sharing across product categories, in contrast to earlier studies which examined component sharing within a specific category. Cross-category component sharing creates the potential for diversified product functionality by transferring new knowledge between categories, in addition to streamlining development, as previously noted. We collected evidence for this proposal from the Japanese digital audio-visual products market in the late 2000s. Panasonic not only shared software modules and the design of large scale integration (LSI) among products in the same category, but also shared them among televisions and DVD recorders. Its competitors, Sony and Sharp, used shared software and the design of LSI only within a product category. Panasonic products were functionally more advanced than those of Sony and Sharp. This study revealed two types of functionality diversification simple functional diversification and linked operations.
\end{abstract}

Keywords: component sharing, across product categories, functional diversification of products, Japanese digital audio-visual products market, new product development performance

\section{Introduction}

This study explores the effect of component sharing across product categories. Existing research has examined component sharing within a product category, showing that this type of component sharing makes development more efficient by reducing the development effort required. ${ }^{1}$ This study suggests that cross-category component sharing creates the potential for diversified product functionality,

1 Cusumano/Nobeoka 1998; Gawer/Cusumano 2002; Halman et al. 2003; Muffatto/Roveda 2000.

*Corresponding author: Sayako Miura, Shujitsu University, Okayama, Japan,

E-mail: sayakomiura@shujitsu.ac.jp. 
which is the result of new knowledge transfer between categories, in addition to the previously noted streamlined development.

We collected evidence for this proposal from the Japanese digital audiovisual products market in the late 2000s. Panasonic not only shared software modules and the design of large scale integration (LSI) among products in the same category, but also used the same architecture for different product categories, including televisions and DVD/Blu-ray (BD) recorders, and shared them. Sharing was easy among digital products composed chiefly of semiconductors and software (which is almost free from physical limitation) and Panasonic exploited these opportunities. Its competitors, Sony and Sharp, used shared software and LSI design within product categories. Panasonic products were functionally more advanced than those of Sony and Sharp. This diversification of functionality, which has not yet received extensive attention in the literature, is the result of the cross-category sharing of components.

\section{Theoretical background}

The existing research into component sharing consists of two groups: intra-firm component sharing within a product category and inter-firm component sharing within a product category. Thought they differ in terms of the scope of sharing, the effect was to improve product development efficiency. ${ }^{2}$

\subsection{Intra-firm component sharing within a product category}

A company can easily share components across various models by creating a common interface between shared and unique components across product models, ${ }^{3}$ which reduces development activities. ${ }^{4}$ This in turn reduces the development cost per model, so a company can efficiently increase the variety of product models. ${ }^{5}$ Diversifying product models according to various customer needs expands market-share. ${ }^{6}$ Studies observe this efficacy effect in product development mainly in the consumer electronics industry ${ }^{7}$ and the auto industry. ${ }^{8}$

2 Cusumano/Nobeoka 1998; Gawer/Cusumano 2002; Halman et al. 2003; Muffatto/Roveda 2000.

3 Baldwin/Clark 2000; Ulrich 1995.

4 Cusumano/Nobeoka 1998.

5 Ulrich 1995.

6 Funk 2004; Cusumano/Nobeoka 1998; Sanderson/Uzumeri 1995.

7 Funk 2002; Sanderson/Uzumeri 1995.

8 Cusumano/Nobeoka 1998; Fisher et al. 1999; Muffatto/Roveda 2000. 
Common components may pose a challenge, in that these may make differentiation among product models difficult. ${ }^{9}$ However, producers can achieve differentiation by using distinct components. ${ }^{10}$ For example, though automobiles share a chassis, product model differentiation can be achieved by using different interiors and exteriors. In addition, differentiation among product models is possible not only through different product features, but also by using different marketing channels and promotions. ${ }^{11}$

\subsection{Inter-firm component sharing within a product category}

Some researchers have investigated inter-firm sharing, wherein standardized components are shared across companies. A company develops and sells standardized components to other companies who use them to develop end products. This enables product variety without excessive increases in product development activities at an industry-wide scale, because there are fewer duplicate components developed and because buyers of the standardized components can develop end products more efficiently. These standardized components also enable new entrants without the knowledge and technology to make the components themselves, which also leads to greater product variety. Studies observe this phenomenon typically in the PC industry: Microsoft sells operating system and Intel sells processors, and various computer makers buy them and develop PCs. ${ }^{12}$

Inter-firm component sharing also has its challenges. Buyers must differentiate their products from competitors using the same standardized components. This must be done through distinct parts and/or differentiated channels and promotions. ${ }^{13}$ Sellers have to convince buyers to use standardized components, often offering technical support to do so. ${ }^{14}$

\subsection{Component sharing across product categories}

According to the intra- and inter-firm component sharing literature, component sharing primarily leads to product development efficiency. However, this research proposes that component sharing diversifies product functions by

9 Desai et al. 2001; Kim/Chhajed 2000; Robertson/Ulrich 1998.

10 Robertson/Ulrich 1998.

11 Kotler/Armstrong 2013.

12 Cusumano 2004; Cusumano/Selby 1995; Gawer/Cusumano 2002.

13 In the PC industry, Dell succeeded in differentiation via direct sales (Dell/Fredman, 1999).

14 Gawer/Cusumano 2002. 


\begin{tabular}{|c|c|c|}
\hline $\begin{array}{l}\text { Cross- } \\
\text { product } \\
\text { category }\end{array}$ & $\begin{array}{l}\text { This } \\
\text { study }\end{array}$ & \\
\hline $\begin{array}{l}\text { Within- } \\
\text { product } \\
\text { category }\end{array}$ & $\begin{array}{c}\text { E.g.: The auto } \\
\text { industry }\end{array}$ & $\begin{array}{c}\text { E.g.: Microsoft } \\
\text { and Intel (PC } \\
\text { Industry) }\end{array}$ \\
\hline
\end{tabular}

Figure 1: Component sharing strategies.

transferring new knowledge between product categories in addition to streamlining development. This new effects comes from cross-product category component sharing in contrast to earlier work which examined component sharing within a specific product category. Figure 1 illustrates the types of component sharing strategies and the position of this research.

Since the early 2000s, cross-product category component sharing has occurred in the consumer electronics industry. Sony developed a digital camcorder, televisions, and DVD recorders using a video and image processing LSI originally developed for the PlayStation 2, a home video game console launched in 2000. ${ }^{15}$ This new type of component sharing may not only streamline product development, but also diversify product functions.

Product development efficiency derives from the same mechanism described in previous studies. Sharing components eliminates duplicate product development activities.

Research on human networking and knowledge transfer can be a basis for exploring whether a cross-product category sharing strategy leads to product functionality diversification. The human networking and knowledge transfer research area suggests that knowledge from disparate products and industries leads to innovation. A technology broker ${ }^{16}$ with a human network in different industries transfers knowledge between industries. The knowledge that is well known in one industry is new to the other industry. Therefore, the transferred knowledge leads to innovation in the new industry. ${ }^{17}$ Transferring knowledge across divisions within a diversified firm can also lead to innovation. ${ }^{18}$ While the knowledge transfer research focuses on human networks, component sharing across product categories may have similar effects because a component from different products may represent new technological knowledge.

15 Nikkei Microdevices (October 2001), p. 65; Nikkei Business (October 4, 2004), p. 42.

16 Hargadon/Sutton 1997.

17 Hargadon/Sutton 1997.

18 Miller et al. 2007; Tsai 2001. 


\section{Research design}

\subsection{Case study}

We employ a case study approach to explore the effects of a cross-product category component sharing strategy because this strategy is a little known phenomenon. ${ }^{19}$ The case study provides an analysis of the Japanese digital audio-visual products market between 2006 and 2010 because both cross- and within-product category component-sharing strategies occurred in this market during this period.

We compare Panasonic, Sony, and Sharp, Japanese electronics companies, in the Japanese television and DVD/BD recorder markets for two reasons. First, they pursued different component sharing strategies. Panasonic used the same architecture for different product categories, televisions and DVD/BD recorders, and shared the software and design of the LSI among these products between 2006 and 2010. This cross-product component-sharing project is called UniPhier. Its competitors, Sony and Sharp, used the same components within one product category only. Therefore, a comparison between these entities allows for an evaluation of a cross-product category component sharing strategy. Second, Panasonic, Sony, and Sharp had large market shares in these products in Japan, making a comparison appropriate.

\subsection{Variables and measurement}

We checked each company's component strategy as the independent variable. As for the dependent variable, we compared the product functionality for Panasonic, Sony, and Sharp. Finally, we also compared development efficiency, because a company can also invest a significant amount of resources to improve product functionality. ${ }^{20}$ Therefore, we verified whether the product improvement was via component sharing or investment.

We used the following sources of magazine and newspaper articles on consumer electronics to determine the component strategy of each company as independent variable: Itmedia, AV Watch, Nikkei Business, Nikkei Microdevices, Nikkei Electronics, and Nikkei Sangyo Shimbun. ${ }^{21}$

19 Eisenhardt 1989; Yin 2013.

20 Productivity data is from Miura (2013).

21 Itmedia. http://www.itmedia.co.jp/ (12/31/2014) and AV Watch. http://av.watch.impress.co. jp/ (12/31/2014). Nikkei Business, Nikkei Microdevices, Nikkei Electronics are printed magazines and Nikkei Sangyo Shimbun is a newspaper. 
To compare the Panasonic product functionality with that of Sony and Sharp, we listed all televisions and DVD/BD recorders launched in the Japanese domestic market from 2006 to 2010 using Kakaku.com, ${ }^{22}$ the most popular website for price comparisons of consumer electronics in Japan, which covers almost all electronics products. We then collected the features for all listed products from company press releases (Panasonic, Sony, and Sharp) and articles on digital consumer electronics product from the magazines Itmedia and $A V$ Watch to create an original database.

To determine product development efficacy, we calculated the number of engineers per product model. ${ }^{23}$ The number of product models was taken from our database. The number of engineers was collected from the listed inventors in patents, which three company applied for from 2006 to 2010, related to video and audio processing technology related to televisions and DVD/BD recorders. While this is not a highly reliable means to measure product development efficacy, it is reasonable.

To measure the input resources of product development, we should ideally measure all resources used, including labour, capital, and materials, though these cannot be measured accurately. Therefore, previous studies measured only labour input. ${ }^{24}$ This research adopts this method.

Previous research measured labour input in terms of person-hours per product development project, which is the amount of work performed by engineers, using a questionnaire survey. ${ }^{25}$ However, we collected the number of engineers from patents. The patent data does not indicate the actual number of engineers who are involved in the product development project or the magnitude of their working hours, though both can be obtained through a questionnaire survey. However, it is still reasonable to measure labour input using patents. We used international patent classification (IPC) and keywords to identify the correct patent for the analysis to know the number of engineers. ${ }^{26}$ Since we compare these companies over a five-year period, an engineer's average working hours at three companies should not differ significantly for this longitudinal period. In addition, patent data is better than that from questionnaires on the point that they are free of retrospective bias. ${ }^{27}$

22 http://kakaku.com/ (12/31/2014).

23 Miura 2013.

24 Clark/Fujimoto 1991; Cusumano/Nobeoka 1998.

25 Clark/Fujimoto 1991; Cusumano/Nobeoka 1998.

26 See Miura (2013) for information that is more detailed.

27 Webb et al. 1981. 
To interpret the data from secondary sources, we held semi-structured interviews with 11 engineers at Panasonic from 2009 to 2012 for a total of 21 hours. They belonged to one of following divisions: television, recorder, or semiconductor - and engaged in the UniPhier project.

\section{The case}

\subsection{Component sharing strategies}

The difference between the component sharing strategies of Panasonic, Sony, and Sharp is whether the components were shared across categories or not. Panasonic made the LSI and software architecture the same for the different product categories, and shared the design of the LSI and software. Figure 2 shows the UniPhier architecture, borne of the UniPhier project. Products developed based on this architecture have been launched since $2006 .^{28}$

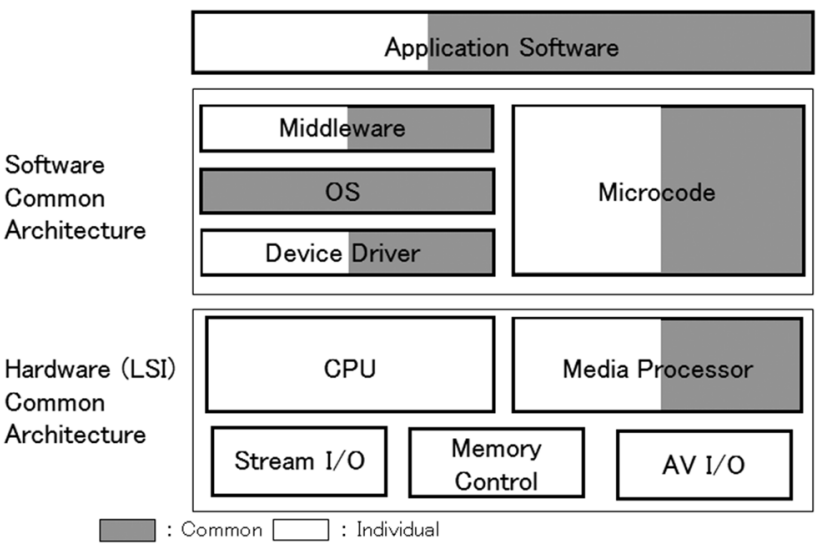

There are two technological changes in the background of this project: the technological progress in semiconductors and digitalization. The increased information processing ability of semiconductors allowed for digital audio-visual products, though also increased the product development burden, especially for software. For example, the software development for DVD recorders grew in 2004
Figure 2: UniPhier architecture. Source: Nikkei Microdevices (October 2004), p. 80, modified by the author.

28 Nikkel Electronics (06/16/2008), p. 104.
} 
to three times that of 2002 since they could process high-definition images. ${ }^{29}$ Simultaneously, the digitalization of audio-visual processing made components easier to share than those for analogue processing because the processing shifted to an integrated circuit and software, which are nearly free from any physical limitations on sharing. Panasonic planned to share the LSI designs and software across categories, and save on development through the opportunities presented by digitalization. The company had already shared these within one category, and aimed to further reduce its product development burden by sharing components beyond a single category. ${ }^{30}$ Its competitors, Sony and Sharp, shared the LSI designs and software only within one product category. ${ }^{31}$

\subsection{Functionality diversification}

Table 1 lists the shared functionality observed across product categories. Grey cells indicate that a company launched products with these functions between 2006 and 2010. When cells for all three companies are coloured, it indicates that they all introduced a product with the functionality listed in the left column. In this case, there is a number in the right column showing the number of months by which Panasonic preceded Sony and Sharp in the introduction of products with the respective functionality. For example, the first column of Table 1 lists AcTVila. After the introduction of televisions with this functionality, Panasonic, Sony, and Sharp launched DVD/BD recorders with this functionality. However, Panasonic introduced DVD/BD recorders with this functionality seven months earlier than Sony, and 19 months earlier than Sharp.

Table 1 demonstrates two points. First, there are two types of functionality diversification: simple diversification and linked operations. Simple functionality diversification is exactly that described in the theoretical development section. By sharing components across product categories, the transferred components diversify the product functionality. For example, Table 1 lists a YouTube function, with which all three companies introduced TV, though only Panasonic launched DVD/BD recorders with this function.

The second functional diversification, linked operations, involves a set of products working together. By using common components, a set of products works smoothly together. For example, HDMI Link enables a customer to use a

29 Nikkei Business (03/28/2005), p. 42.

30 Nikkei Electronics (08/11/2004), pp. 117-123.

31 Usually it is difficult to cooperate across product divisions. Panasonic successfully managed the UniPhier project (Miura 2011). 


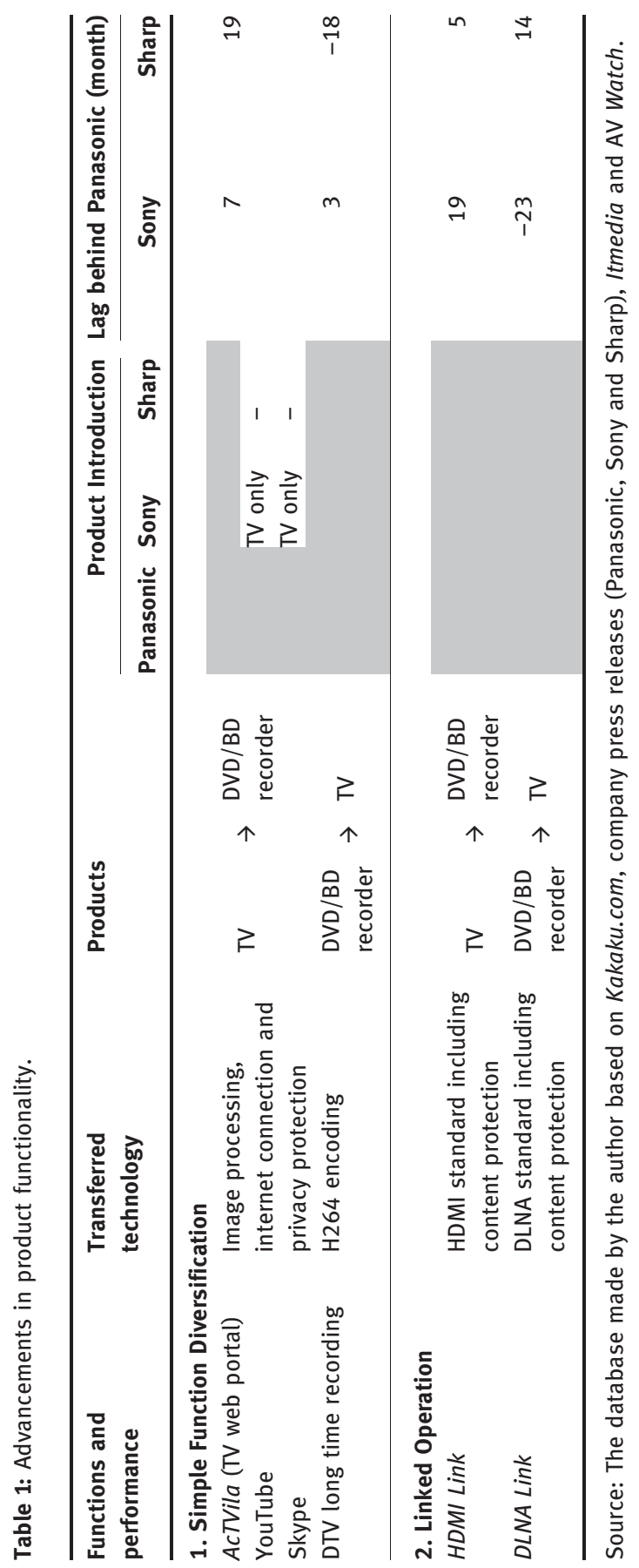


single remote control to operate both a television and a DVD/BD recorder. DLNA Link makes it possible to watch recorded content on a DVD/BD recorder on a TV in a different room. Both functionalities provide convenient home entertainment systems when televisions and DVD/BD recorders work together.

Table 1 also indicates Panasonic's superiority to Sony and Sharp in these areas. For simple functionality diversification, Panasonic is superior to Sony and Sharp, except for Sharp's TV with long DTV recording times. In terms of linked operations, Panasonic exceeded Sony and Sharp, except for Sony's TV with DLNA Link.

\subsection{Product development productivity and knowledge transfer}

Panasonic is superior to other companies in launching products with functionalities matching products in different categories. However, it is important to investigate whether these are realized through component sharing. Because functional diversification can be achieved by investing significantly in development, we investigated development productivity by the number of engineers per product model and interviewed Panasonic engineers.

Table 2 shows the number of engineers per product model, which indicates product development labour productivity. For televisions, Panasonic has the fewest engineers per product model, implying that Panasonic was more productive than the other companies were. For DVD/BD recorders, Panasonic is as productive as Sharp, and more productive than Sony. Since Panasonic achieved better product functionality than Sharp, Panasonic was more productive. This analysis indicates that Panasonic did not achieve product functionality diversification by investment.

Table 2: Engineers per product model.

\begin{tabular}{llrrr}
\hline Product & Company & $\begin{array}{r}\text { Engineers per } \\
\text { product model }\end{array}$ & $\begin{array}{r}\text { Number } \\
\text { of engineers }\end{array}$ & $\begin{array}{r}\text { Number of } \\
\text { introduced models }\end{array}$ \\
\hline TV & Panasonic & 4.68 & 234 & 50 \\
& Sony & 6.71 & 255 & 38 \\
& Sharp & 5.76 & 340 & 59 \\
DVD/BD Recorder & Panasonic & 3.14 & 135 & 43 \\
& Sony & 6.00 & 156 & 26 \\
& Sharp & 3.23 & 100 & 31 \\
\hline
\end{tabular}

Source: Data is from Miura (2013), pp. 58 and 63, modified by the author. 
This analysis focuses on product models introduced in the Japanese market and Japanese patents. However, the companies introduced the products worldwide. Therefore, the number of engineers per model may not reflect reality, because these engineers might develop products for markets outside Japan. To avoid this issue, we investigated two kinds of data. First, the models introduced from 2006 to 2010 in the US market, the largest market in the world, were investigated using CNET. $^{32}$ Second, we collected the number of engineers by using patents, which affiliated companies of each company outside Japan applied for.

We counted registered products in the CNET site, and checked whether it was introduced in the U.S. by using the each company's U.S. support site. Panasonic and Sharp regarding the number of television models introduced, which was 43 for Panasonic, 41 for Sharp, and 55 for Sony. This means that the index, engineers per model, underestimates Sony's efficiency as compared to Panasonic and Sharp. However, in the case of Sony, we excluded the engineers (that is inventors listed in patents) outside of Japan. In Panasonic's case, patents belonging to inventors who did not seem Japanese, inferred from their names and addresses, were nonetheless applied for by Panasonic Japan. Therefore, such patents were included in the analysis. However, Sony U.S.A. and entities in countries other than Japan applied for patents of Sony with such inventors (that is, inventors outside Japan), and these were excluded from the analysis. Regarding Sharp, patents did not include such inventors. In total, these facts imply that Panasonic's labour productivity was the same or less than that of its competitors, and it did not invest much to achieve functional diversification.

As for DVD/BD recorders, the same procedures were applied. Panasonic introduced 22 models of recorders, Sony introduced 18 models, and Sharp did not introduce any models. This fact implies that Panasonic did not invest significantly to achieve functional diversification.

This labour productivity analysis consists with the interview data. As for Internet-related functionality, Panasonic introduced its recorders with AcTVila seven months earlier than Sony and 19 months earlier than Sharp. In addition, only Panasonic introduced TVs and recorders with YouTube and Skype functionality. Sony introduced only TVs with these functions and Sharp introduced no products with these functions. Panasonic could easily transfer software modules from televisions to recorders to realize these functions because of the UniPhier common architecture, without which it is difficult or costly for a company to perform such transfers. Takizawa, a Panasonic engineer for DVD/ BD recorders, said: "As for AcTVila, it was very easy to transfer it from

32 http://www.cnet.com/ (12/31/2014). 
televisions to recorders because of UniPhier. However, engineers at other companies said that it was too difficult to transfer." 33 Fukuda, another engineer working on the same product line, had the same view: "To make recorders with internet functions would have required hundreds more engineers. Because there is a common architecture, the recorders division did not need a lot of development for these television functions." 34

We cannot exclude the possibility that Sony and Sharp made a strategic decision that recorders did not require internet-related functionality. However, Panasonic created this functional diversification efficiently by transferring software modules originally developed for televisions to DVD/BD recorders.

Panasonic introduced DVD/BD recorders with HDMI Link so that a television and a recorder could operate via one remote control, a product launched five months earlier than Sharp, and 19 months earlier than Sony. Panasonic could do this because televisions and recorders shared the same architecture, easing the process of sharing the video and audio processing circuit and software. Kubo, a Panasonic engineer at a semiconductor company, said: "Because our codec hardware and software for video and sound have the same architecture, it was easy to transfer them and make HDMI Link. Even without any special development, we could create it. However, competitors must make significant development efforts to create the same features."35

This linked functionality, named VIERA Link, was successful in the market, increasing the combined sales of televisions and DVD/BD recorders. ${ }^{36}$ Kubo also pointed out: "When competitors saw this feature, they invested a lot to develop the same functionality." This is Panasonic's view, not that of Sony or Sharp, though Panasonic efficiently realized a linked operation that was successful in the marketplace.

\section{Discussion and conclusions}

The case study of the Japanese digital audio-visual product market in the late 2000s indicates that component sharing creates a functional diversification

\footnotetext{
33 Interview with Shinichiro Takigawa (03/31/2011), translated by the author.

34 Interview with Hideki Fukuda (01/16/2012), translated by the author.

35 Interview with Tokuaki Kubo (11/25/2009), translated by the author.

36 The combined sales accounted for 40 to $50 \%$ of the sales in some stores (ITmedia: 04/04/ 2007: http://www.itmedia.co.jp/lifestyle/articles/0704/13/news048.html (12/31/2014). Panasonic senior managing director, Toshizo Ushimaru said "It is a hidden huge hit", (Nikkei Sangyo Shimbun (08/22/2006), p. 3).
} 
effect. This is a new finding, in addition to the efficiency effect known from the previous literature, which focused only on component sharing within a product category. The cross-product category component sharing strategy has recently emerged because of the technological progress made in the fields of semiconductors and digitalization. Sharing components with a wide range of products creates functional diversification because the knowledge behind these products is diverse. Since even more technological progress is expected in the fields of semiconductors and digitalization, this type of component sharing will expand hereafter, and greater functional diversification effects will be manifested.

This study revealed two types of functional diversification: simple functional diversification and linked operations. Linked operations represent a new type of differentiation, wherein a group of products from different categories work together. It is therefore possible for a company to create differentiation based on a group of products rather than a standalone product, which has been the focus of extant studies on marketing.

However, the finding regarding functional diversification is based on a single case study. Further studies using more cases could verify the finding. Future research into component sharing across product categories could focus on the demerits of sharing resulting from some kinds of product attributes, since the software and circuits of the LSI of digital products are easier to share than automobile engines, for example, because of differences relating to physical limitations. Based on the ease of sharing, the effects could differ. The types of products and the effects of a cross-product categories sharing strategy should be classified and examined in future research.

Funding: This work was supported by JSPS KAKENHI Grant Number 25885035.

\section{Bibliography}

Baldwin, Carliss Y./Clark, Kim B. (2000): Design Rules, Vol. 1: The Power of Modularity. Cambridge: The MIT Press.

Clark, Kim B./Fujimoto, Takahiro (1991): Product Development Performance: Strategy, Organization, and Management in the World Auto Industry. Boston: Harvard Business School Press.

Cusumano, Michael A. (2004): The Business of Software: What Every Manager, Programmer, and Entrepreneur Must Know to Thrive and Survive in Good Times and Bad. New York: Free Press.

Cusumano, Michael A./Nobeoka, Kentaro (1998): Thinking Beyond Lean: How Multi-project Management is Transforming Product Development at Toyota and Other Companies. New York: Free Press. 
Cusumano, Michael A./Selby, Richard W. (1995): Microsoft Secrets: How the World's Most Powerful Software Company Creates Technology, Shapes Markets, and Manages People. New York: Free Press.

Dell, Michael/Fredman, Catherine (1999): Direct from Dell: Strategies That Revolutionized an Industry. New York: Harper Collins.

Desai, Preyas et al. (2001): "Product Differentiation and Commonality in Design: Balancing Revenue and Cost Drivers". Management Science 47.1: 37-51.

Eisenhardt, Kathleen M. (1989): "Building Theories from Case Study Research". The Academy of Management Review 14.4: 532-550.

Fisher, Marshall et al. (1999): "Component Sharing in the Management of Product Variety: A Study of Automotive Braking Systems". Management Science 45.3: 297-315.

Funk, Jeffery L. (2002): Global Competition between and within Standards: The Case of Mobile Phones. London: Palgrave.

Funk, Jeffrey L. (2004): "The Product Life Cycle Theory and Product Line Management: The Case of Mobile Phones". IEEE Transactions on Engineering Management 51.2: 142-152.

Gawer, Annabelle/Cusumano, Michael A. (2002): Platform Leadership: How Intel, Microsoft, and Cisco Drive Industry Innovation. Boston: Harvard Business School Press.

Halman, Johannes I. M. et al. (2003): "Platform-Driven Development of Product Families: Linking Theory with Practice". Journal of Product Innovation Management 20.2: 149-162.

Hargadon, Andrew/Sutton, Robert I. (1997): "Technology Brokering and Innovation in a Product Development Firm”. Administrative Science Quarterly 42.4: 716-749.

Kim, Kilsun/Chhajed, Dilip (2000): “Commonality in Product Design: Cost Saving, Valuation Change and Cannibalization”. European Journal of Operational Research 125.3: 602-621.

Kotler, Philip/Armstrong, Gary (2013): Principles of Marketing, 15th ed. Upper Saddle River: Prentice-Hall Inc.

Miller, Douglas J. et al. (2007): "The Use of Knowledge for Technological Innovation within Diversified Firms". Academy of Management Journal 50.2: 308-326.

Miura, Sayako 三浦紗綾子 (2011): “Kotonaru Seihin o Taisho to Shita Platform Kaihatsu” 異なる製品を対象としたプラットフォーム開発. Ikkyokenkyu一橋研究 35.4: 15-32.

Miura, Sayako 三浦紗綾子 (2013): Buhinshisutem Kyoyu no Koka 部品システム共有の効果. Hitotsubashi University Ph. D. dissertation一橋大学大学院博士論文.

Muffatto, Moreno/Roveda, Marco (2000): “Developing Product Platforms: Analysis of the Development Process". Technovation 20.11: 617-630.

Robertson, David/Ulrich, Karl (1998): “Planning for Product Platforms". Sloan Management Review 39.4: 19-31.

Sanderson, Susan/Uzumeri, Mustafa (1995): “Managing Product Families: The Case of the Sony Walkman”. Research Policy 24.5: 761-782.

Tsai, Wenpin (2001): “Knowledge Transfer in Intraorganizational Networks: Effects of Network Position and Absorptive Capacity on Business Unit Innovation and Performance". The Academy of Management Journal 44.5: 996-1004.

Ulrich, Karl (1995): "The Role of Product Architecture in the Manufacturing Firm". Research Policy 24.3: 419-440.

Webb, Eugene J. et al. (1981): Nonreactive Measures in the Social Sciences. Boston: Houghton Mifflin.

Yin, Robert K. (2013): Case Study Research: Design and Methods, 5th ed. Thousand Oaks: Sage Publications. 